\title{
Seizure Resistance of Coatings in Four Ball Tests, Two Roller Tests and Gear Tests*
}

\author{
Yoshio TERAUCHI**, Hiromasa NADANO*** \\ and Masaki KOHNO****
}

\begin{abstract}
To clarify the seizure resistance and the frictional characteristics of rollers with various coatings, two roller tests on rollers coated with copper, graphite and molybdenum disulfide were carried out using an Amsler machine, and the flash temperature rise on the contacting surface when the rollers were seized was calculated. Further, the correlation between the test result of seizure resistance in the two roller machine and the previous test results in a power-circulating gear machine and in a Soda-type four ball machine was examined, and the frictional characteristics of the coatings were estimated. From the experimental results, a correlation between the seizure resistance in the two roller tests and the scoring resistance in the gear tests was recognized. Also, the variation in the coefficient of friction in the two roller tests was different from that in the four ball tests.
\end{abstract}

Key Words: Gear, Lubrication, Coatings, Seizure Resistance, Two Roller Test, Four Ball Test, Gear Test

\section{Introduction}

It can be considered that the load-carrying capacity against scoring of gears increases when the tooth surfaces of the gears are coated with coatings whose smoothness, lubricity, thermal properties etc. are excellent. The authors carried out scoring tests ${ }^{(1) \sim(3)}$ on gears with various coatings, using a powercirculating gear machine, and seizure tests ${ }^{(3)(4)}$ on balls with various coatings, using a four ball machine, and examined the scoring resistance of the gears and the seizure resistance of the balls from a standpoint of the surface temperature.

In this report, to clarify the seizure resistance and the frictional characteristics of rollers with various coatings, two roller tests on rollers coated with cop-

\footnotetext{
Received 11th June, 1986. Paper No. 85-1179 A

** Faculty of Engineering, Hiroshima University, Shitami, Saijo-cho, Higashi-Hiroshima-shi, Hiroshima, 724 Japan

*:* Kure National College of Technology, 2-11. AgaMinami 2-chome, Kure-shi. Hiroshima, 737 Japan

wask Kure National College of Techmology
}

per, graphite and molybdenum disulfide were carried out, using an Amsler machine with an improved load unit.

Investigating the correlation between the seizure resistances in the four ball test, two roller test and gear test is an important issue. However, there have been few investigations ${ }^{(5)}$ of this problem. In this report, therefore, the test result of seizure resistance in the two roller machine was compared with the previous test results in the gear machine and in the four ball machine, and the correlation between the seizure resistances of the coatings in the three tests was examined.

\section{Experimental method}

\subsection{Test specimens}

Table 1 shows the specifications of the test balls and the test rollers, and Table 2 shows those of the test gears. The balls (rotatory and stationary balls) were normalized at $443 \mathrm{~K}$ after quenching at $1173 \mathrm{~K}$. and a coating treatment was applied to their surfaces. Before coating, the balls had an average sphericity of $0.12 \mu \mathrm{m}$ and their surface had a Vickers microhatd. ness of approximately $800 \mathrm{HIV}$. 
The rollers (barrel and cylinder type rollers) were oil-quenched at $1073 \mathrm{~K}$ after being carburized at $1173 \mathrm{~K}$, then they were ground. Their surface had a Vickers microhardness of approximately $720 \mathrm{HV}$. To grind the barrel type roller, a grinder in which the grinding wheel rounds the roller in a concave circular arc, was used. Before coating, the surface roughness, in the circumferential direction, of the barrel and cylinder type rollers, was approximately $3 \mu \mathrm{m} R_{\max }$ and $2 \mu \mathrm{m} R_{\max }$, respectively. The roughness in the axial direction of the barrel and cylinder type rollers was approximately $6 \mu \mathrm{m} R_{\max }$ and $3 \mu \mathrm{m} R_{\max }$, respectively. The gears were ground by a Reishauer gear grinding machine after being gas-carburized.

Table 1 Specifications of test balls and test rollers

\begin{tabular}{l|l|c|r|r}
\hline & Test piece & $\begin{array}{c}\text { Diameter } \\
\mathrm{mm}\end{array}$ & $\begin{array}{c}\text { Width } \\
\mathrm{mm}\end{array}$ & Material \\
\hline \multirow{2}{*}{$\begin{array}{l}\text { Four bal1 } \\
\text { test }\end{array}$} & Rotatory ball & 19.05 & - & \multirow{2}{*}{ SUJ2 } \\
\cline { 2 - 5 } & Stationary bal1 & 19.05 & - & \\
\hline $\begin{array}{l}\text { Two roller } \\
\text { test }\end{array}$ & Barre1 & 40.0 & 10 & \multirow{2}{*}{ SCM415 H } \\
\cline { 2 - 5 } & Cylinder & 40.0 & 10 & \multirow{2}{*}{}
\end{tabular}

* Crowning radius : $20 \mathrm{~mm}$

Table 2 Specifications of test gears

\begin{tabular}{|c|c|c|}
\hline & Pinion & Whee 1 \\
\hline Number of teeth $z$ & 18 & 40 \\
\hline Center distance mm & \multicolumn{2}{|c|}{116} \\
\hline Pressure angle $a_{0}$ & \multicolumn{2}{|c|}{$20^{\circ}$} \\
\hline Module & \multicolumn{2}{|c|}{4} \\
\hline Backlash $\quad S_{n} \quad \mathrm{~mm}$ & \multicolumn{2}{|c|}{0.5} \\
\hline Face width B & \multicolumn{2}{|c|}{10} \\
\hline $\begin{array}{lc}\text { Effective } & \text { face } \\
\text { width } & B_{f} \\
\end{array}$ & \multicolumn{2}{|c|}{7} \\
\hline Tooth profile & \multicolumn{2}{|c|}{ Standard } \\
\hline $\begin{array}{l}\text { Pitch circle } \\
\text { diameter do }\end{array}$ & 72 & 160 \\
\hline $\begin{array}{c}\text { Outside diameter } \\
\mathrm{d}_{1} \mathrm{~mm} \\
\end{array}$ & 80 & 168 \\
\hline Material & \multicolumn{2}{|c|}{ SCM $415 \mathrm{H}$} \\
\hline
\end{tabular}

Table 3 Condition of coating treatment and thermal conductivity of surface layer for each test piece

\begin{tabular}{|c|c|c|c|}
\hline Test & Surface treatment & \multicolumn{2}{|c|}{$\begin{array}{l}\text { Thermal conductivity of } \\
\text { surface layer W/(mK) }\end{array}$} \\
\hline$M$ & $\mathrm{MoS}_{2} \operatorname{coating}$ & \multicolumn{2}{|r|}{0.14} \\
\hline \multirow[b]{2}{*}{$U$} & \multirow{2}{*}{ Uncoated } & SUJ2 & 27.6 \\
\hline & & SCM $415 \mathrm{H}$ & 24.0 \\
\hline$G$ & Graphite coating & \multicolumn{2}{|r|}{151} \\
\hline $\mathrm{C}$ & Cu-plating & \multicolumn{2}{|r|}{379} \\
\hline
\end{tabular}

\section{2 Coating treatment}

Table 3 shows the condition of coating treatment and the thermal conductivity of the surface layer for each test piece. The procedure of the coating treatment has been described in the previous report ${ }^{(2)}$. In all cases, a pair of the test pieces was coated with the same material and the surface layer was approximately $10 \mu \mathrm{m}$ in thickness.

The thermal conductivities of the $\mathrm{Cu}$ film (pair $\mathrm{C}$ ) and the graphite film (pair G) are better than those of base metals SUJ2 and SCM415H of the test pieces. Therefore, the surface temperatures for pairs $C$ and $G$ can be considered to be comparatively low. On the other hand, the thermal conductivity of the $\mathrm{MoS}_{2}$ film (pair M) is extremely small.

\subsection{Test machine}

The four ball test was carried out using a Sodatype four ball machine. A normal load was applied by exerting oil pressure on a bowl in the test machine. With respect to the measurement of frictional force, the displacement of the plate spring contacting a part of the bowl was detected by a strain gauge.

The two roller test was carried out using an Amsler machine in which the load unit was improved so that the load could be controlled by oil pressure. The oil pressure acted on the machine frame with an upper roller, and then the load was measured by a load sensor. With respect to the measurement of frictional force, the displacement of the pendulum mounted on the shaft of the test machine was detected by a differential transformer.

The gear test was carried out using a powercirculating gear machine.

\subsection{Test conditions}

Table 4 shows the test conditions for the four ball test (FB), the two roller tests (TR1, TR2) and the gear test $(\mathrm{GE})$. In the case of the four ball test, the normal load was increased during the initial 10 s and was kept constant for $20 \mathrm{sec}$. In the case of the two roller tests, the load was increased during the initial $10 \mathrm{sec}$ and was kept constant for $50 \mathrm{sec}$. In the case of the gear test, the rotational speed of the pinion was increased stepwise (18 increments) at a constant normal load per unit face width of $266 \mathrm{~N} / \mathrm{mm}$. When a scoring failure did not occur in the speed range, the tooth load was increased stepwise (10 increments) to $390 \mathrm{~N} / \mathrm{mm}$ at a constant pinion speed of $10372 \mathrm{rpm}$. The four ball machine and the two roller machine were continuously run until seizure occurred. On the other hand, the gear machine was stopped for more than 2 hours after running in each respective range.

\subsection{Lubricating oil}

The test pieces were lubricated with \#140 turbine oil (with viscosities of $28 \times 10^{-6} \mathrm{~m}^{2} / \mathrm{s}$ at $323 \mathrm{~K}$ and $8 \times$ 
Table 4 Test conditions in each test

\begin{tabular}{|c|c|c|c|c|c|c|}
\hline & \multirow[t]{2}{*}{ Test piece } & \multirow{2}{*}{$\begin{array}{l}\text { Revolution } \\
\text { speed rpm }\end{array}$} & \multirow{2}{*}{$\begin{array}{l}\text { Specific } \\
\text { sliding } \\
\end{array}$} & \multicolumn{2}{|c|}{ Normal load $P_{n}$} & \multirow{2}{*}{$\begin{array}{l}\text { Time of unit } \\
\text { test range }\end{array}$} \\
\hline & & & & Initial load & Increment & \\
\hline \multirow{2}{*}{$\begin{array}{ll}\text { Four ball } \\
\text { test } & (\mathrm{FB}) \\
\end{array}$} & Rotatory ball & 500 & 1 & \multirow{2}{*}{$46.0 \mathrm{~N}$} & \multirow{2}{*}{$40.0 \mathrm{~N}$} & \multirow{2}{*}{$30 \mathrm{~s}$} \\
\hline & Stationary ball & 0 & $-\infty$ & & & \\
\hline \multirow{2}{*}{$\begin{array}{l}\text { Two roller } \\
\text { test (TR1) }\end{array}$} & Barrel & 344 & -2.07 & \multirow{2}{*}{$974 \mathrm{~N}$} & \multirow{2}{*}{$243 \mathrm{~N}$} & \multirow{2}{*}{$1 \mathrm{~min}$} \\
\hline & Cylinder & 1056 & 0.67 & & & \\
\hline \multirow{2}{*}{$\begin{array}{l}\text { Two ro1ler } \\
\text { test (TR2) }\end{array}$} & Cylinder & 344 & -2.07 & \multirow{2}{*}{$97.4 \mathrm{~N} / \mathrm{mm}$} & \multirow{2}{*}{$24.3 \mathrm{~N} / \mathrm{mm}$} & \multirow{2}{*}{$1 \mathrm{~min}$} \\
\hline & Cylinder & 1056 & 0.67 & & & \\
\hline \multirow{2}{*}{$\begin{array}{c}\text { Gear test } \\
\text { (GE) }\end{array}$} & Pinion & $2000 \sim 10372$ & $-6.68^{(a)}$ & \multirow[b]{2}{*}{$266 \mathrm{~N} / \mathrm{mm}$} & $12.0 \mathrm{~N} / \mathrm{mm}^{(\mathrm{c})}$ & \multirow{2}{*}{$\begin{array}{l}4.4 \times 10^{4} \\
\text { revolutions }(d)\end{array}$} \\
\hline & Whee 1 & $900 \sim 4667$ & $0.87^{(b)}$ & & $(10372 \mathrm{rpm})$ & \\
\hline
\end{tabular}

(a) Root of pinion

(b) Tip of whee 1

(c) The load was increased after the tests of 18 speed ranges were finished.

(d) Total revolutions of pinion

Table 5 Lubricating methods in each test

\begin{tabular}{c|l|c|c}
\hline Test & $\begin{array}{l}\text { Lubricating } \\
\text { method }\end{array}$ & $\begin{array}{l}\text { Supply rate of } \\
\text { oil } \\
\text { L/min }\end{array}$ & $\begin{array}{l}\text { Initial oil } \\
\text { temperature } K\end{array}$ \\
\hline FB & $\begin{array}{l}\text { Bath } \\
\text { lubrication }\end{array}$ & -303 \\
\hline TR1 & $\begin{array}{l}\text { Forced } \\
\text { TR2 }\end{array}$ & 0.3 & 293 \\
\hline GE & $\begin{array}{l}\text { Forced } \\
\text { lubrication }\end{array}$ & 0.6 & $323^{*}$ \\
\hline
\end{tabular}

$10^{-6} \mathrm{~m}^{2} / \mathrm{s}$ at $363 \mathrm{~K}$ ) which was a straight mineral oil without additives. The lubricating methods in each test are shown in Table 5. In the case of the four ball test, a rotatory ball (upper ball) was immersed about $1 / 3$ of its diameter into the oil bath. In this case, the oil temperature rose with the lapse of running time, and it reached a maximum temperature of approximately $323 \mathrm{~K}$. The two roller tests were carried out under forced lubrication and the oil was sprayed onto the engaging side of the rollers. In this case, the oil temperature in the oil tank (about 20L) reached a maximum temperature of approximately $313 \mathrm{~K}$. Similarly, the gear test was carried out under forced lubrication, and the oil was sprayed onto the meshing faces of the gears.

\section{Test results and observations}

\subsection{Coefficient of friction}

The relation between the coefficient of friction $\mu$ and the normal load $P_{n}$ per unit ball in the four ball test FB is shown in Fig. 1, where the symbol $S$ indicates that seizure occurred in the next test range. The measurement of the coefficient of friction was carried out two times for each ball pair, and one of two measured values which had the same tendency was shown.

In the load range between about $0.2 \mathrm{kN}$ and 0.65 $\mathrm{kN}$, the coefficients of friction for ball pairs $\mathrm{M}\left(\mathrm{MoS}_{2}\right.$ coating), G (graphite coating) and $\mathrm{C}$ (Cu-plating)

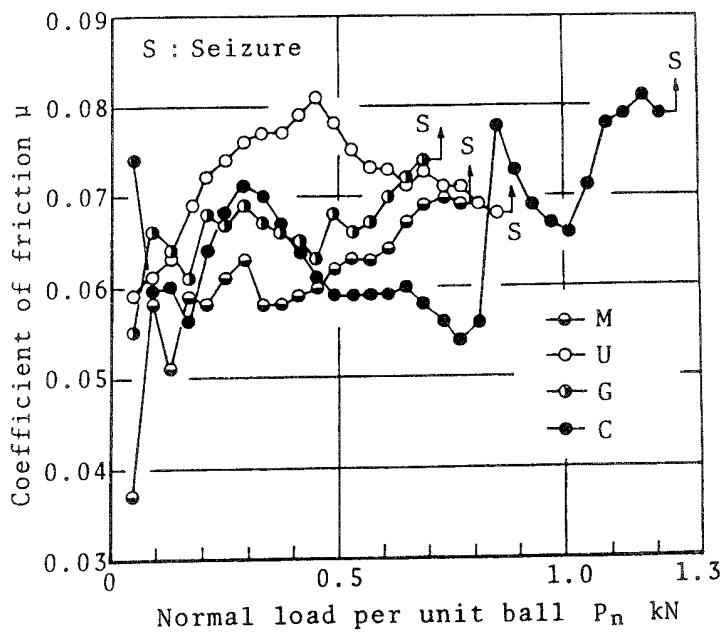

Fig. 1 Relation between coefficient of friction and normal load per unit ball in four ball test

were smaller than that for ball pair $U$ (uncoated). Particularly, in the case of ball pair $C$, when the load exceeded $0.3 \mathrm{kN}$, the coefficient of friction decreased with increasing load. When the load was about $0.8 \mathrm{kN}$, the coefficient of friction for ball pair $\mathrm{C}$ had a minimum value. After that, however, it rapidly increased with increasing load. Although the coefficient of friction transiently decreased, it suddenly increased and seizure occurred. The coefficient of friction for ball pairs with coatings, just before seizure occurred, was approximately equal to or larger than that for an uncoated ball pair.

The relation between the coefficient of friction and the normal load in two roller test TR 1 , where the pair of test rollers consists of a barrel and a cylinder type rollers, is shown in Fig. 2. The measturement of the coefficient of friction was carried out more than result three times for each roller pair and the typical test result was shown. For all the roller pairs, the coefficient of friction, just after running the tests, had 
a maximum value and it decreased with increasing load. Particularly, in the case of roller pair $C$, the initial coefficient of friction was extremely high and it rapidly decreased. As for this behavior, it appears that the surface layer of the rollers was uniformly worn down due to the frictional force and wear process, and the contacting surface became smooth.

The variation in the coefficient of friction in two roller test TR 1 , where the rollers contact in a rollingsliding condition, is different from that in the four ball test, where the balls contact in a purely sliding condi-

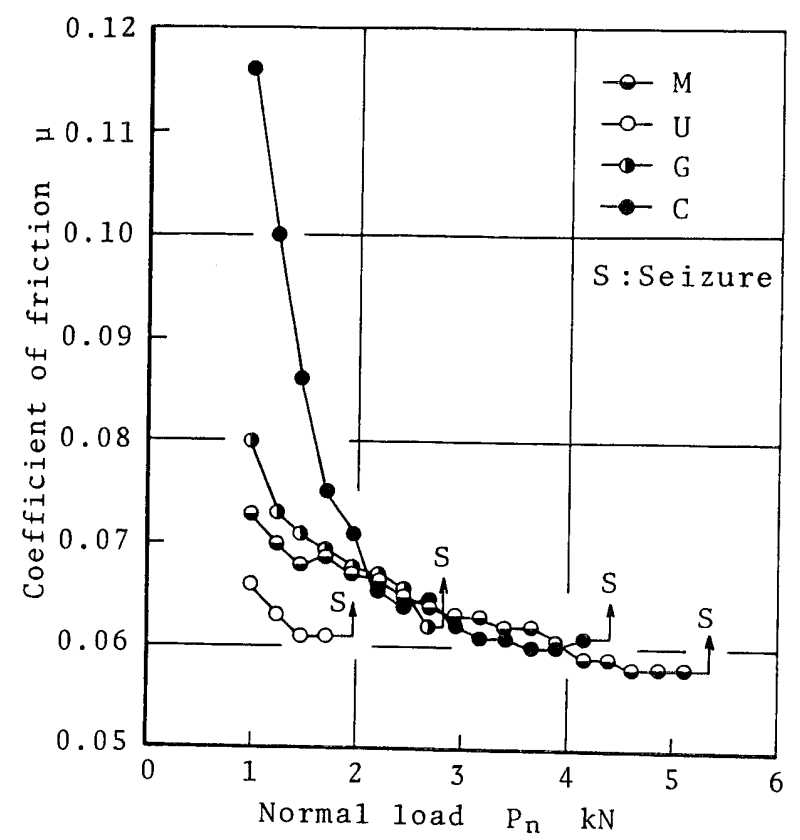

Fig. 2 Relation between coefficient of friction and normal load in two roller test TR1

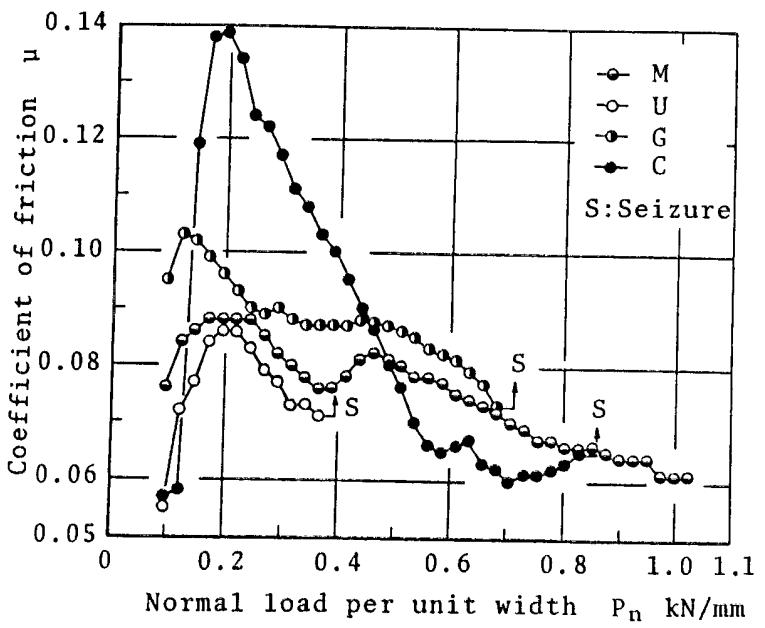

Fig. 3 Relation between coefficient of friction and normal load per unit contact width in two roller test TR2 tion. The increase in the coefficient of friction, just before seizure occurred, that was observed in the four ball test was not observed in two roller test TR1 and the coefficient of friction was approximately 0.06 for all the roller pairs.

The relation between the coefficient of friction and the normal load per unit contact width in two roller test TR2, where the rollers consist of two cylinders, is shown in Fig. 3. In this case, the test for roller pair $M$ was stopped at $P_{n}=1.02 \mathrm{kN} / \mathrm{mm}$ because the load exceeded the load-carrying capacity of the test machine. For all the roller pairs, the coefficient of friction, just after running the tests, was comparatively small. After that, the coefficient of friction increased, reached a maximum value, then decreased with increasing load.

The variation in the coefficient of friction in two roller test TR2, where the rollers were assumed to have line contact, had a similar tendency as that in two roller test TR1, where the rollers were assumed to have point contact. However, the coefficient of friction in the former was larger than that in the latter, except in the initial test ranges.

\subsection{Seizure resistance}

Figure 4 shows the calculated value of the maximum Hertzian stress $\sigma_{H}$ when seizure (or scoring) occurred. In the gear test, since scoring failure occurred at the meshing position where the root of the pinion mated with the tip of the wheel, the values of the sliding velocity and the Hertzian stress at this position (where the Hertzian stress was 1.28 times as large as that at the pitch point) are shown. The arrow mark in the figure indicates that the test was stopped before seizure occurred, and the value of the Hertzian stress at the last test range $\left(P_{n}=1.02 \mathrm{kN} / \mathrm{mm}\right.$ in test

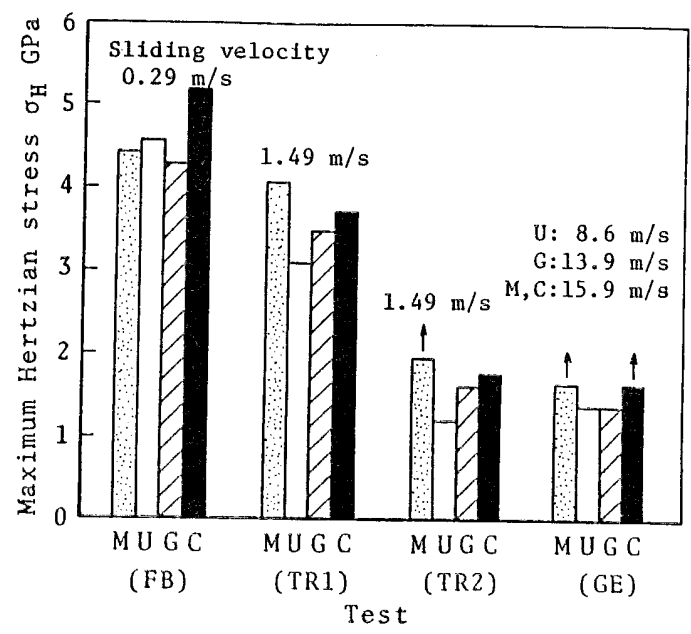

Fig. 4 Calculated value of maximum Hertzian stress when seizure occurred 
TR2 and $P_{n}=390 \mathrm{~N} / \mathrm{mm}$ in test GE) is shown.

With respect to the effect of the test method on seizure resistance, for the cases of two roller test TR2 and the gear test, the Hertzian stresses when seizure occurred are less than $2 \mathrm{GPa}$. On the other hand, those for the cases of the four ball test and two roller test TR1 are considerably larger than the compressive yield strength of the material. Therefore, it can be considered that the contacting surface was plastically deformed in the initial test range. In addition, for the case of ball pair $\mathrm{C}$, the diameter of the wear Scar of the stationary balls was considerably larger than that of the Hertzian contact zone.

With respect to the effect of the coating treatment on seizure resistance, the seizure resistance in two roller tests TR1 and TR2 and the scoring resistance in the gear test are smaller in the descending order of $\mathrm{MoS}_{2}$ coating, Cu-plating, graphite coating and uncoated pair. Therefore, a correlation between the seizure resistance in the two roller tests and the scoring resistance in the gear test is recognized. On the contrary, in the case of the four ball test, the seizure resistance for ball pairs $M$ and $G$ is a little smaller than that for ball pair $U$. Therefore, a correlation between the two roller tests or gear test results and the four ball test results was not observed.

As an example, for the case of pair $M$, the EHD oil film thickness in the last test range was calculated by Dowson's equation ${ }^{(6)}$. In the case of the gear test, it was $0.49 \mu \mathrm{m}$ at the meshing position where the root of the pinion mated with the tip of the wheel. The oil film thickness in two roller test TR2 was $0.19 \mu \mathrm{m}$ and it was smaller than that in the gear test.

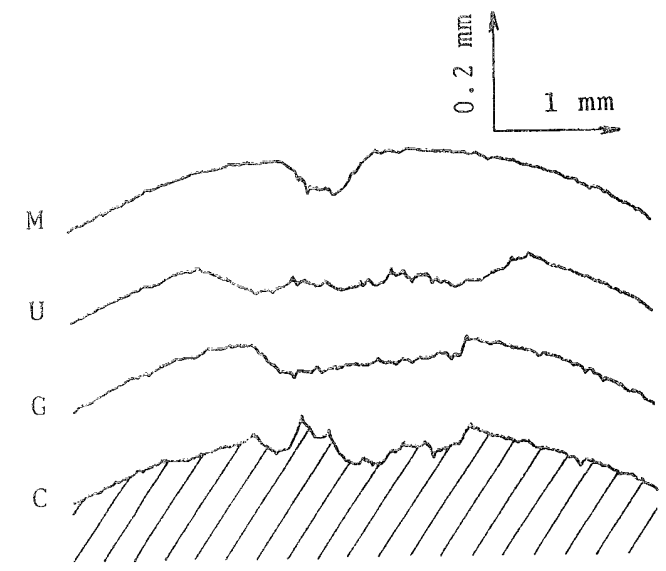

(a) Barrel type roller

\subsection{Surface feature}

As an example, for the case of two roller test TR1, the profile of the wear track in the axial direction of the rollers, after seizure occurred, is shown in Fig. 5. It was measured by a surface profilometer. For all the barrel type rollers, a hollow with a depth of about $0.1 \mathrm{~mm}$ occurred on the wear track, and the base metal was exposed. On the contrary, for the cylinder type rollers, except roller pair $\mathrm{M}$, a part of the surface protruded considerably. In the case of two roller tests, the peripheral velocity of the cylinder type roller was approximately three times as large as that of the barrel type roller and the bulk-temperature of the former was different from that of the latter. Consequently, it seems that, as soon as seizure occurred, a part of the base metal of the barrel type roller was sheared and was transferred to the contacting surface of the cylinder type roller $^{(7)}$.

Similarly, for the case of roller pairs $\mathrm{M}$ and $\mathrm{C}$ in two roller test TR1, the photographs of the wear tracks of the cylinder type roller, just before and after seizure occurred, are shown in Fig. 6. The photographs just before and after seizure occurred were individually obtained by using additional test rollers. To obtain a photograph just before seizure occurred, the test machine was stopped at the initial stage when

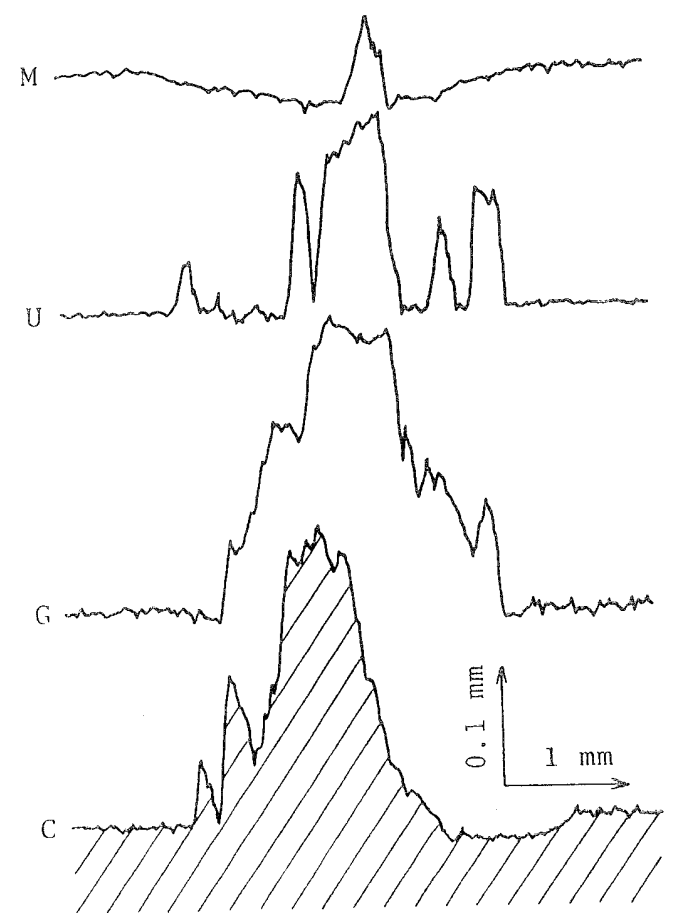

(b) Cylinder type roller

Fig. 5 Profile of wear track in axial direction of rollers after seizure occurred in two roller test TRI 
the coefficient of friction increased due to seizure.

For both roller pairs, after seizure occurred, the base metal of the cylinder type roller was exposed in the wear track, and the wear tracks were extremely rough. On the other hand, the wear tracks just before seizure occurred were comparatively smooth. Therefore, it can be considered that surface failure by seizure rapidly progressed when seizure occurred.

In addition, the calculated values of the Hertzian contact zone in the axial direction of the cylinder type roller were $1.98 \mathrm{~mm}$ for roller pair $\mathrm{M}$ and $1.81 \mathrm{~mm}$ for roller pair $\mathrm{C}$, and they were smaller than the measured values of the width of the wear track.

\subsection{Flash temperature rise}

At present, the surface temperature of a gear tooth (which consists of the sum of the flash and bulk-temperatures) can be considered to be an important index for estimating the scoring resistance of gears. Therefore, when the scoring resistance is estimated from the calculation of the surface temperature, it is necessary to exactly evaluate the flash temperature and the bulk-temperature (which is defined as the surface temperature just before the gear teeth mate with each other). However, it is complicated to exactly estimate the bulk-temperature in each test. In this report, therefore, the flash temperature rise of the contacting surfaces in the two roller and the gear tests was calculated, and their relation was examined.

Figure 7 shows the calculated values of the flash temperature rise when seizure occurred in the two

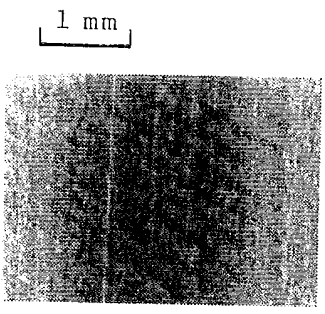

(a) Pair M just before seizure

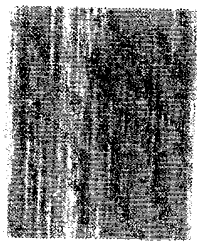

(c) Pair C just before seizure

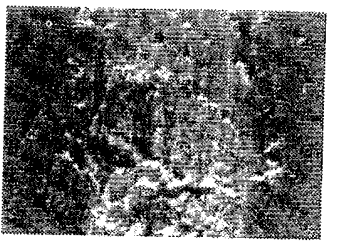

(b) Pair $M$ after seizure

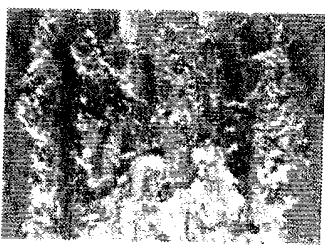

(d) Pair C after seizure

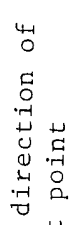

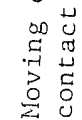

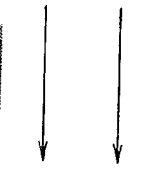

Fig. 6 Photographs of wear tracks of cylinder type roller just before and after seizure occurred in two roller test TRI roller and the gear tests. In this figure, the flash temperature rise for roller pair $\mathrm{M}$ in two roller test TR2 and that for gear pairs $\mathrm{M}$ and $\mathrm{C}$ in the gear test are the values in the last test range. The flash temperature rise was calculated by the equation ${ }^{(8)}$ for a temperature rise caused by a moving heat source, in which the distribution of the heat intensity was assumed to be parabolic, when the heat source moved on a body whose thermal properties in the surface layer were different from those in the core.

In this equation, the coefficient of friction $\mu$ for the rollers was given by the measured value just before seizure occurred, and that for the gears was calculated by $\mu=0.1 V_{0}^{-0.2(9)}$, where $V_{0}$ is the peripheral velocity $(\mathrm{m} / \mathrm{s})$ at the pitch point. In the latter case, the coefficient of friction was 0.054 for gear pair $\mathrm{U}$, 0.049 for gear pair $\mathrm{G}$, and 0.048 for gear pairs $M$ and C. For the case of roller test TR1, the maximum value of the heat intensity per unit time $q_{0}$ was calculated with the assumption that the heat quantity per unit time of an ellipsoidally distributed heat source generated on a contacting surface due to frictional heat $Q^{\prime}$ is equal to that of a parabolically distributed heat source $Q$. The load-sharing of the gears was calculated by dividing the reciprocal of the deformation of the meshing pair of the teeth by the sum of the reciprocal of the deformation of each meshing pair of teeth. The thickness of the coated film when seizure occurred was assumed to be $0.1 \mu \mathrm{m}$ for all the tests.

With respect to the effect of the test method on

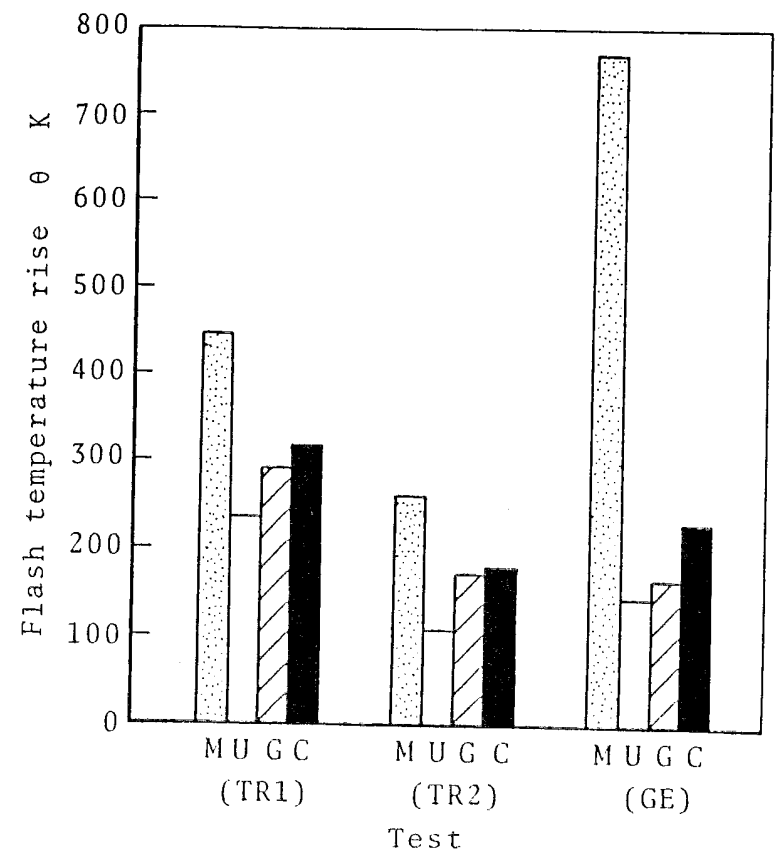

Fig. 7 Calculated value of flash temperature rise when seizure occurred in two roller and gear tests 
the flash temperature rise when seizure occurred, as shown in Fig. 7, the flash temperature rise for two roller test TR1 is higher than that for two roller test TR2 or the gear test, except for gear pair M. On the other hand, with respect to the effect of the coating treatment on the flash temperature rise when seizure occurred, the flash temperature rise is lower in the descending order of pairs $\mathrm{M}, \mathrm{C}, \mathrm{G}$ and $\mathrm{U}$, and this order agrees well with the order of seizure resistance.

Just after seizure occurred (after the test machine stopped), the bulk-temperatures of roller pair $\mathrm{C}$ were measured by a contact-type thermister thermometer. The mean value of the bulktemperatures of the rollers in roller test TR1 was approximately $347 \mathrm{~K}$ and that in roller test TR2 was approximately $403 \mathrm{~K}$. In addition, the bulktemperature of the gear teeth just after the last test range for gear pair $\mathrm{C}$ was approximately $356 \mathrm{~K}$. Therefore, it is seen that the orders of the measured values of the bulk-temperature and those of the calculated values of the flash temperature rise are reversed.

From the calculated results of the surface temper ature rise of the balls in the four ball test ${ }^{(4)}$, the flash temperature rise for ball pair $\mathrm{C}(417 \mathrm{~K})$ was lower than that for ball pair $\mathrm{U}(489 \mathrm{~K})$. Therefore, a correlation between this result and the calculated results of the flash temperature rise in the roller tests and the gear test was not observed.

\section{Conclusions}

The two roller tests were carried out using an Amsler machine, and the seizure resistance and the frictional characteristics of the rollers with various coatings were clarified. Further, the test result in the two roller machine was compared with the previous test results in the gear machine and in the four ball machine. The results are summarized as follows:

(1) The seizure resistance in two roller tests
TR1 and TR2 and the scoring resistance in the gear test are smaller in the descending order of $\mathrm{MoS}_{2}$ coating, Cu-plating, graphite coating and uncoated pair. Therefore, a correlation between the seizure resistance in the two roller tests and the scoring resistance in the gear test is recognized.

(2) The variation in the coefficient of friction in two roller test TR2, where the rollers were assumed to have line contact, had a similar tendency as that in two roller test TR1, where the rollers were assumed to have point contact. In the two roller tests, an increase in the coefficient of friction just before seizure occurred, that was observed in the four ball test, was not observed.

(3) The calculated value of the flash temperature rise when seizure occurred, for two roller test TR1, is higher than that for two roller test TR2 or the gear test, except for gear pair M.

\section{References}

(1) Terauchi, Y., Nadano, H. and Kohno, M., Bull. JSME, Vol. 27, No. 232 (1984), p. 2287.

(2) Terauchi, Y., Kohno, M., Nadano, H. and Nakamoto, Y., Bull. JSME, Vol. 29, No. 247 (1986), p. 235.

(3) Terauchi, Y., Nadano, H. and Kohno, M., Trans. ASME, J. Mech. Transm. Autom. Des., Vol. 108, No. 1 (1986), p. 127.

(4) Terauchi, Y., Nadano, H. and Kohno, M., J. JSLE, Int. Ed., No. 7 (1986), p. 129.

(5) Naruse, C. and Haizuka, S., J. JSLE (in Japanese), Vol.21, No. 12 (1976), p. 832.

(6) Dowson, D., Proc. Inst. Mech. Eng., Vol. 182, No. Pt. 3A (1967-68), p. 151.

(7) Terauchi, Y., Miyao, Y. and Nadano, H., Bull. JSME, Vol. 13, No. 63 (1970), p. 1123.

(8) Terauchi, Y., Miyao, Y. and Nadano, H., Bull. JSME, Vol. 16, No. 99 (1973), p. 1443.

(9) ISO/TC $60 / \mathrm{WG} 6$, Netherlands, 17, Calculation of Scoring Resistance of Gear Drives, (1975-3). 